\title{
Assessment and Improvement Model Plan for the Current Situation of Water Resources Problems
}

\author{
Shi Feng \\ North China Electricity Power University, Baoding 071000, China; \\ 1361214913 @qq.com
}

Keywords: water resources problems, evaluation model, assuming tips

\begin{abstract}
With the rapid deterioration of the world's water resources problem, we need a set of assessment and improvement plan for the current situation. Firstly, with the authoritative historical data, we establish the evaluation model for water-supply ability to measure the ability of a region to provide clean water resources to meet the needs of its population, which can reflect the water resources bearing capacity of a region simply and reliably. Secondly, considering that the reason and degree of water shortage are both different in different regions, so we manage to build the Quadratic Fuzzy Evaluation Model. Then when it comes to the driving factors of water shortage in Shandong Province, we establish the optimal allocation model of water resources and manage to apply it to Shandong Province. We achieve the optimal allocation of the water usage in Shandong Province, which means reaching the maximum economic benefit and the minimum environmental pollution target at the same time. By the total quantity control, we can provide scientific advice and basis for the relevant departments, which can analyze and deal with the situation of the severe water shortage in Shandong Province well. Finally, we test and evaluate the advantages and disadvantages of the model and propose an improved scheme.
\end{abstract}

\section{Introduction}

According to the United Nations, one quarter of the world's population is experiencing water scarcity as a result of the increasing population which is followed by more personal consumption,more industrial consumption and more pollution that depletes he supply of fresh water.We definite "clean water" as the water that ranks 1 to 4 according to the National Water Resources Bulletin .The factors can be summarized as physical scarcity and economic scarcity. The physical scarcity is where there is inadequate water in a region to meet demand. Economic scarcity is where water exists but poor management and lack of infrastructure limits the availability of clean water.And now, a suitable evaluation model for a region's water-supply ability is needed , and an intervention plan need to be made.

\section{The models}

In this paper, we used several different models for this problem instead of focusing on one single approach, and this is more sufficient for complex system. Our goal is to measure the ability of a region to provide clean water to meet the needs of its population.

Models we use:

1)To consider about the factors above all round, we develop an evaluation model containing 3 sub models, which are the Markov Model, the Logistic Model and the Quadratic Fuzzy Evaluation Model, aiming to assess the ability of a region providing clean water roundly.

2)The Markov Model is used to predict the water-supply situation ,which is influenced by the underground water $\left({ }^{W_{u}}\right)$,the surface water $\left({ }^{W_{s}}\right)$ which needs to subtract the water carried from other regions by rivers $\left(W^{\circ}\right)$, the clean water from the sea, the rainfall or other natural resources( $\left.W_{\mathrm{n}}\right)$, in the future few years. 
3)The Logistic Model is used to predict the water consumption situation by working out the influence that the growing population makes to the agricultural consumption( ${ }^{U_{\text {a }}}$ ), the industrial consumption $\left({ }^{U_{i}}\right)$, the domestic consumption $\left({ }^{U}\right.$ d $)$ and the ecological consumption $\left({ }^{U_{e}}\right)$.

4)The Quadratic Fuzzy Evaluation Model is used to decide what factor is the main one that leads to the lack of water in each part of the region by figuring out the membership degrees of each factor. With the models above, we can measure the ability of a region to provide water rather accurately and work out a suitable an intervention plan to release the water usage pressure.

\section{Application of the Markov Model}

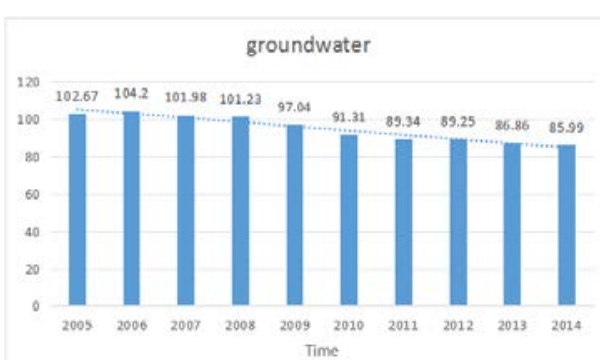

Figure1: the quantity of underground water

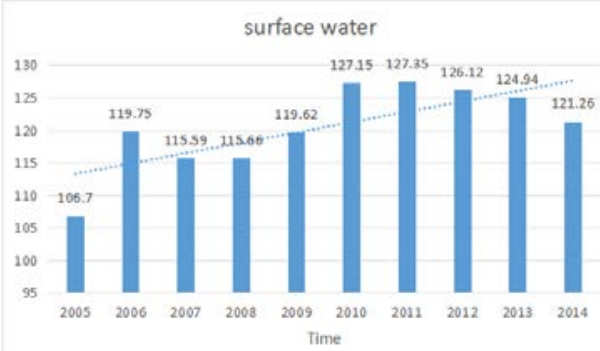

Figure 3:the quantity of surface water

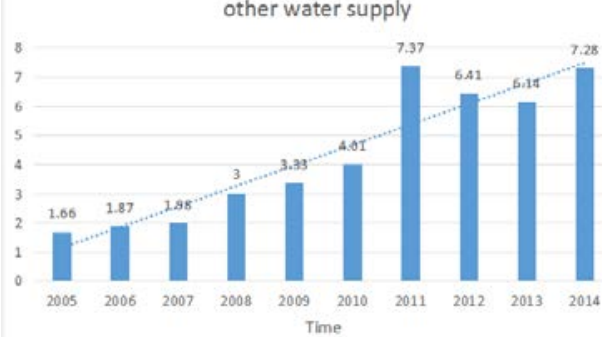

Figure 4:the quantity of other natural water

With the data of the total quantity of the underground water, the surface water an-d the inter-basin water fr om2005 to 2014, we can work out that the annual growth rates as following:

Table 1: the growth rates of four sources

\begin{tabular}{cccc}
\hline Groundwater & Surface water & other natural sources & Inter-basin water \\
\hline$-1.93 \%$ & $1.54 \%$ & $20.73 \%$ & $3.24 \%$ \\
\hline
\end{tabular}

From Table 1,we can see that the growth rate of the clean water from the sea or other natural sources is too big to be reasonable .So we conclude that the Markov Model is not fit for this aspect. Instead, we use the linear fitting to find out the relationship between the water from other natural sources and time.

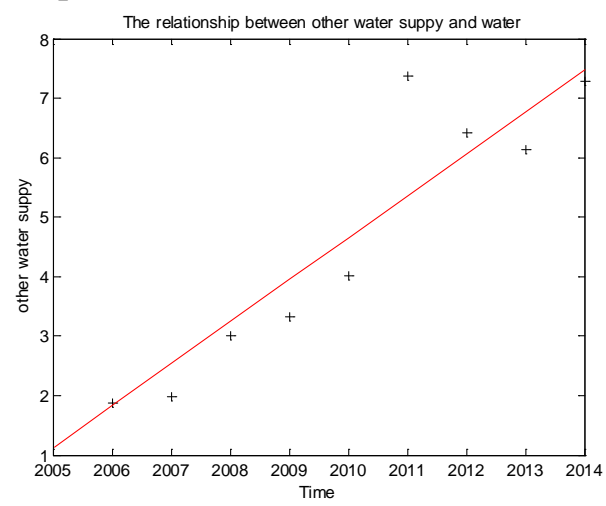

Figure 5:the relationship between other natural sources and time 


\section{Conclusion}

Obviously, $Z$ is less than 1 ,so Shandong Province doesn't have the ability to provide enough clean water to meet the needs of its population in the future 15 years. Furthermore, $Z$ is less than 0.75 ,so we can infer that Shandong Province is lack of clean water seriously and needs water carry from other regions.

The optimal allocation of water resources can be realized by engineering measures and non-engineering measures. Its effects are as following:

1)In terms of demand:

- Construct water-saving society by ajusting the industrial structure;

- Adjust the distribution of productive forces to suppress the growth of the need for water in order to adapt to the adverse natural water conditions

2)In terms of supply:

- Regulate water distribution in the industry, and strengthen the management of water;

- Change the spatial distribution of water resources by means of engineering measures in order to adapt to the productivity layout;

The two aspects work together to achieve the target.

\section{Literature References}

According to Professor LA.Zadeh from University of Pennsylvania of United States, the more membership degree close to 1,the higher the degree that $x$ belongs to $R$, which means the greater the impact of the corresponding factors.

From the 5 matrices $U_{1} U_{2} U_{3} U_{4} U_{5}$, we can conclude that most cities in Shandong Province are short of water because its lack of natural water resources ,especially Dongying, Laiwu , Dezhou , Rizhao and Jining. As for the economical scarcity, the water environment of Jinan,Zibo,Yantai,Liaocheng, and Linxi are very bad, which means that water there may be polluted seriously and poor management and lack of infrastructure limits the availability of clean water.

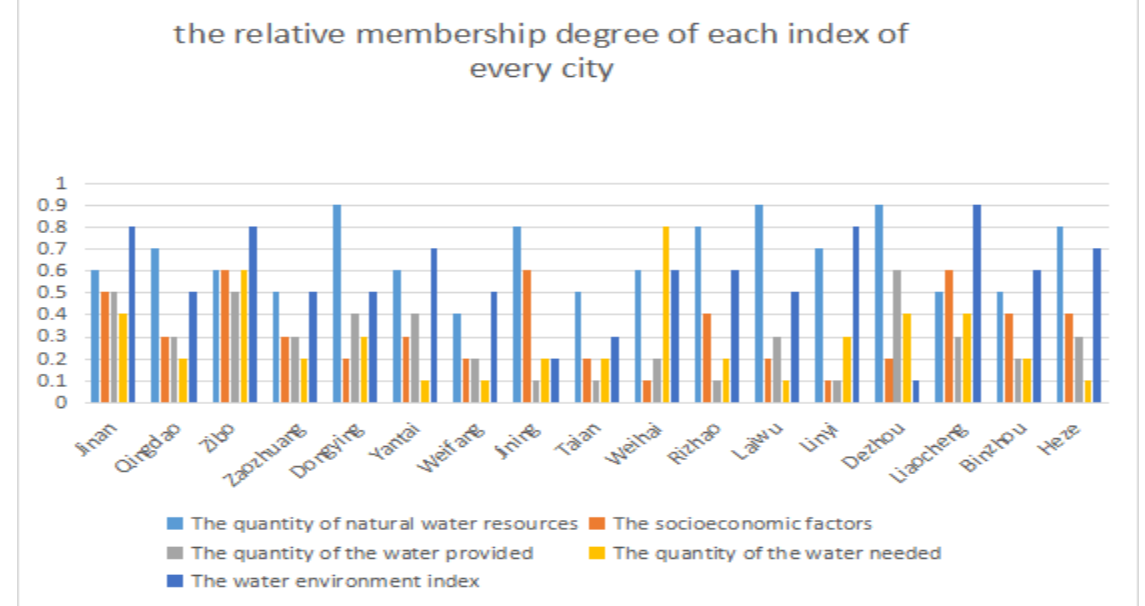

Figure 6: the relative membership degree of each index of every city

From the matrix $T$ and Table 1,we can classify the 17 cities as the ones facing serious water shortage ,which includes Qingdao,Yantai, Weifang, Taian, Weihai and Laiwu; the ones facing slight water shortage ,which includes Dongying and Linxi; the ones facing normal water shortage ,such as Jinan, Zibo, Zaozhuang, Jining, Rizhao, Dezhou and Liaocheng.

In this way, we can release the water usage pressure depending on the different situations. 


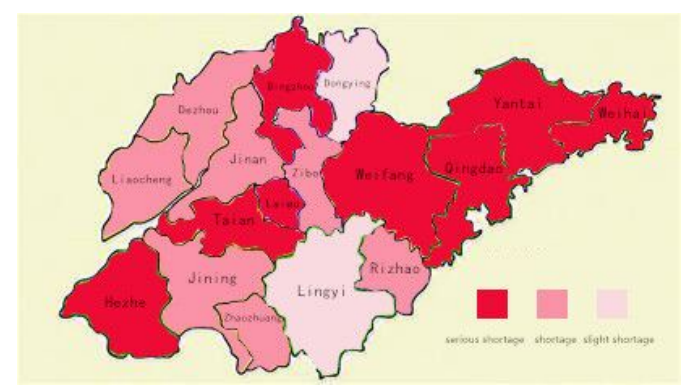

Figure 7: the water shortage degree of different cities in Shandong Province

\section{References}

[1] J. van der Geer, J.A.J. Hanraads, R.A. Lupton, The art of writing a scientific article, J. Sci. Commun. 163 (2000) 51-59.

Reference to a book:

[2] W. Strunk Jr., E.B. White, The Elements of Style, third ed., Macmillan, New York, 1979. Reference to a chapter in an edited book:

[3] G.R. Mettam, L.B. Adams, How to prepare an electronic version of your article, in: B.S. Jones, R.Z. Smith (Eds.), Introduction to the Electronic Age, E-Publishing Inc., New York, 1999, pp. 281-304.

[4] R.J. Ong, J.T. Dawley and P.G. Clem: submitted to Journal of Materials Research (2003)

[5] P.G. Clem, M. Rodriguez, J.A. Voigt and C.S. Ashley, U.S. Patent 6,231,666. (2001)

[6] Information on http://www.weld.labs.gov.cn 